\title{
XLVII. A memoir on some new modifications of galvanic apparatus, with observations in support of his theory of galvanism
}

\section{R. Hare M.D.}

To cite this article: R. Hare M.D. (1821) XLVII. A memoir on some new modifications of galvanic apparatus, with observations in support of his theory of galvanism , Philosophical Magazine Series 1, 57:276, 284-294, DOI: 10.1080/14786442108652504

To link to this article: http://dx.doi.org/10.1080/14786442108652504

曲 Published online: 27 Jul 2009.

Submit your article to this journal

Џll Article views: 2

Q View related articles $\longleftarrow$ 


\section{4}

XLVII. A Memoir on some new Modifications of Galvanic Apparatus, with Olservations in Support of his Theory of Galvanism. By R. HAkE, M.D. Professor of Chemistry in the Universily of Pennsylvania*.

I HAD observed that the ignition produced by one or tro galvanic pairs attained its highest intensity, almost as soon as they were covered by the acid used to excite them, aud ceased soon afterwards ; although the action of the acid should have increased during the interim. I had also reniarked, in using an apparatus of three hundred pairs of small plates, that a platina wire of Number 16 , placed in the circuit, was fused in consequence of a construction which enabled me to plunge them all nearly at the same time. It was therefore conceived, that the maximum of effect in Voltaic apparatus of extensive series had never been attained. The plates are generally arranged in distinct troughs rarely containing more than twenty pairs Those of the great apparatris of the Royal Institution, employed by Sir H. Davy, had only ten pairs in each. There were une hundred such to be successively placed in the acid, and the whole connected ere the poles could act. Consequently the effect which arises immediately after immersion, would be lost in the troughs first arranged, hefore it could be produced in the last; and no effort appears to have been made to take advantage of this transient accumulation of power, either in using that magnificent combination, or in any other of which I have read. In order to observe the consequence of simultaneous immersion with a series sufficiently numerous to test, the correctness of my expectations, a galvanic apparatus of eighty concentric coils of copper and zine, was so suspended by a heam and levers, as that they might be made to descend into, or rise out of the acid in an instant. The zinc sheets were about nine inches by six, the copper fourteen by six; more of this metal being necessary, as in every coil it was made to commence within the zinc, and completely to surround it without. The sheets were coiled so as not to leave between them an interstice wider than a quarter of an inch. Each coil is in diameter about two inches and a half, so that all may descend freely into eighty glass jars two inches and three quarters diameter inside, and eight inches high, duly stationed to receive them.

My apparatus being thus arranged, two small lead pipes were severally soldered to each pole, and a piece of charcoal about a quarter of an inch thick, and an inch and a half long, tapering a little at each extremity, had these severally inserted into the

* Communicated by the Autho:. 
hollow ends of the pipes. The jars being furnished with diluted acid and the coils suddenly lowered into them, no vestige of the charcoal could be seen. It was ignited so intensely, that those portions of the pipes by which it had been embraced were destroyed. In order to avoid a useless and tiresome repetition, I will here state that the coils were only kept in the acid while the action at the poles was at a maximum in the experiment just mentioned, and in others which I am about to describe, unless where the decomposition produced by water is spoken of, or the sensation excited in the hands. I designate the apparatus with which I performed them, as the galvanic deflagrator, on account of its superior power, in proportion to its size, in causing deflagration ; and as, in the form last adopted, it differs from the voltaic pile in the omission of one of the elements heretofore deemed necessary to its construction.

Desirous of seeing the effect of the simultaneous immetsion of my series upon water, the pipes soldered to the poles were introduced into a vessel containing that fluid. No extraordinary effect was perceived, until they were very near, when a vivid flash was observed, and happening to touch almost at the same time, they were found fused and incorporated at the place of contact. I next soldered to each pipe a brass cylinder of about five-tenths of an inch bore. These cylinders were made to receive the tapering extremities of a piece of eharcoal about two inches long so as to complete the circuit. The submersion of the coils caused the most vivid ignition in the coal. It was instantaneously and entirely on fire. A piece of platina of about a quarter of an inch diameter in connexion with oue pole, was instantly fused at the end on being brought in contact with some mercury communicating with the other. When two cylinders of charcoal having hemispherical terminations were fitted into the brass cylinders and brought nearly into contact, a most vivid ignition took place, and continued after they were removed about a half or three quarters of an inch apart, the interval rivalling the sun in brilliancy. The igneous fluid appeared to proceed from the positive side. The charcoal in the cylinder soldered to the latter would be intensely ignited throughout when the piece conrected with the negative pole was ignited more towards the extremity approaching the positive. The most intense action seems to arise from placing a platina wire of about the eighth of an inch diameter, in connexion with the positive pole, and bringing it in contact with, and afterwards removing it a small distance apart from a piece of charcoal (fresh from the fire) affixed to the other pole.

As points are pre-eminently capable of carrying off (without being injured) a current of the electrical fluid, and very ill qualified to conduct caloric; while, by facilitating radiation, charcoal fa- 
vours the separation of caloric from the electricity which does not radiate; this result seems consistent with my hypothesis, that the fluid as extricated by Volta's pile is a compound of caloric and elcctricity*; but not with the other hypothesis, which supposes it to be electricity alone. The finest needle is competent to discharge the product of the most powerful machire without detriment, if receiver gradually as generated by them. Platina points, as small as those which were melted like wax in my experiments, are used as tips to lightning rods without injury, unless in sudden discharges produced uncer peculiar circumstances $\nmid$.

The following experiment I conceive to be very unfavourable to the idea that galvanic ignition arises from a current of electricity.

A cylinder of lead of about a quarter of an inch diameter, and about two inches long, was reduced to the thickness of a common brass pin for about three quarters of an inch. When one end was connected with one pole of the apparatus, the other remained suspended by this filament; yet it was instantaneously fused by contact with the other pole. As all the calorific fluid which acted upon the suspended knob, must have passed through the filament by which it hung, the fusion could not have resulted from a pure electrical current, which would have dispersed the filament ere a mass fifty times larger had been perceptibly affected. According to my theory, caloric is not separated from the electricity until

* According to the theory here alluded to, the galvanic fiuid owes its properties to caloric and electricity; the former predominating in proportion to the size of the pairs, the latter in proportion to the number, being in both cases excited by a powerful acid. Hence in batteries which combine both qualifications sufficiently, as in all those intervening between Children's large pairs of two feet eight inches by six feet, and the 2000 four-inch pairs of the Royal Institution, the phænomena indicate the presence of both fluids. In $D \in$ Lue's column, where the size of the pairs is insignificant, and the energy of interposed agents feeble, we see electricity evolved without any appreciable quantity of caloric. In the calorimotor where we have size only, the number being the lowest possible, we are scarcely able to detect the presence of electricity.

When the fluid contains enough electricity to give a projecille power adequate to pass through a small space in the air, or through charcoal, which impedes or arrests the caloric, and favours its propensity to radiate, this principle heat is evolved. This accounts for the evolution of intense heat under those circumstances which rarifies the air, so that the length of the jet from one pole to the other may be extended after its commencement. Hence the portions of the circuit nearest to the intervening charcoal, or heated space, are alone injured; and even non-conducting bodies, as quart $z$, introduced into it are fused, and hence a very large wire may be melted by the fluid, received through a small wire imperceptibly affected.

See Silliman's Journal, No. 6, Vol. 1. Thomson's Annals, Sept. 1810. Tilloch's Philosophical Magazine, October 1819.

* See Adams's Electricity, On points. 
circumstances very much favour a disunion, as on the passage of the compound fluid through charcoal, the air, or a vacuum. In operating with the deflagrator, I have found a brass knob of about five tenths of an inch in diameter, to burn on the superficies only; where alone, according to my view, caloric is separated so as to act on the mass. Having, as mentioned in the memoir on my theory of galvanism, found that four galvanic surfaces acted well in one recipient, I was tempted by means of the eighty coils to extend that construction. It occurred to me that attempts of this kind had failed from using only one copper for each zine plate. The zinc had always been permitted to react towards the negative as well as the positive pole. My coils being surrounded by copper, it seemed probable, that, if electro-caloric were, as I had suggested, carried forward by circulation arising from galvanic polarity, this might act within the interior of the coils, yet not be exerted between one coil and another.

I had accordingly a trough constructed with a partition along the middle, so as to receive forty coils on one side, and a like number on the other. This apparatus when in operation excited a sensation scarcely tolerable in the backs of the hands. Interposed charcoal was not ignited as easily as before; but a most intense ignition took place on bringing a metallic point connected with one pole of the series, into contact. with a piece of charcoal fastened to the other. It did not take place, however, so speedily as when glasses were used; but soon after the ignition was effected it became even more poiverful than before. A cylinger of platina nearly a quarter of an inch in diameter, tapering a little at the end, was fused, and burned so as to sparkle to a considerable distance around, and fall in drops. A ball of brass of about half an inch diameter was seen to burn on its surface with a green flame. Tin foil, or tinsel rolled up into large coils of about three quarters of an inch tlick, were rapidly destroyed, as was a wire of platina of No. 16. Platina wires in connexion with the poles were brought into contact with sulphuric acid; there was an appearance of lively ignition, but strongest on the positive side. Excepting in its power of permenting charcoal, the galvanic fluid seemed to be extricated with as much force as when each coil was in a distinct glass. Apprehending that the partition in the trough did not sufficiently insulate the poles from each other, as they were but a few inches apart, moisture or moistened wood intervening, I had two troughs made, each to hold forty pairs, and took care that there should be a dry space about four inches broad between them. They were first filled with pure river water, there being no saline nor acid matter to infuence the plates, unless the very minute quantity which might have remained on them from former immersions. Yet the sensation pro- 
duced by them, on the backs of my hands, was painful ; and a lively scintillation took place when the poles were approximated. Dutch gold leaf was not sensibly burned, though water was found decomposable by wires properly affixed. No effect was produced on potash, the heat being inarlequate to fuse it.

A mixture of nitre aud sulphuric acid was next added to the water in the troughs, afterwards charcoal from the fire was vividly ignited; and when attached to the positive pole a steel wire was interposed between it and the other pole, the most vivid ignition which I ever saw was induced. I should deem it imprudent to repeat the experiment without glasses, as my eyes, though unusually strong, were affected for forty-eight hours afterwards. If the intensity of the light did not produce an optical deception, by its distressing influence upon the organs of vision, the charcoal assurred a pasty consistence, as if in a state approaching to fusion. -That charcoal should be thus softened, without being destroyed by the oxygen of the atmosphere, will not appear strange, when the power of galvanism in reversing chemical affinities is remembered; and were it otherwise, the air conld have 110 access, first, be causeof the excessive rarefaction, and in the next place, as I suspect, on account of the volatilization of the carbon forming ahout it a circumambient atmosphere. This last-mentioned impression arose from observing, that when the experiment was performed in vacuo, there was a lively scintillation, as if the carbon in an aëriform state acted as a supporter of combustion on the metal.

A wire of platina (No. 16) was fused into a globule on being connected with the positive pole, and brought into contact with a piece of pure hydrate of potash, situated on a silver tray in connexion with the other pole. The potash became red hot, and was deflagrated rapidly with a flame having the rosy hue of potassuretted hydrogen.

The great apparatus of the Royal Institution, in projectile power was from six to eight times nore potent than mine. It produced a discharge between charcoal points when removed about four inches apart, whereas mine will not produce a jet at more than three fourths of an inch. But that series contained 2000 pairs, mine is only about a twenty-fifth part as large.

A steel wire of about one tenth of an inch in diameter, affixed to the negative pole, was passed up through the axis of an open necked inverted bell glass filled with water. A platina wire, No. 16, attached to a positive pole, being passed down to the steel wire, both were fused together, and, cooling, could not be separated by manual force.-Immediately after this incorporation of their extremities, the platina wire became incandescent for a space of some inches above the surface of the water. 
A piece of silvered paper about two inches square was folded up, the metallic surface outward, and fastened into vices affixed to the poles. Into each vice a wire was screwed at the same time. The fluid generated by the apparatus was not perceptibly conveyed by the silvered paper, as it did not prevent the wires severally attached to the poles from decomposing water or producing ignition by contact.

In my memoir on my theory of galvanism I suggested, that the decomposition of water, which Wollaston effected by mechanical electricity, might not be the effect of divellent attraction like those excited by the poles of a voltaic pile, but of a mechanical concussion, as when wires are dispersed by the discharge of an electrical battery. In support of that opinion I will now observe, that he could not prevent bydrogen and oxygen from being extricated at each wire, instead of hydrogen being given off only at one, and oxygen at the other, as is invariably the ease when the voltaic pile is employed. That learned and ingenious philosopher, in concluding his account of this celebrated experiment, says, "but in fact the resemblance is not complete, for in every way in which I have tried it, I observed each wire gave out both oxygen and hydrogen gas, instead of their being formed separately as by the electric pile."

Is it not reasonable to suppose that an electrical shock may dissipate any body into its elementary atoms, whether simple or compound, so that no two particles would be left together which can be separated by physical means?

Looking over Singer's Electricity, a recent and most able modern publication, I find that in the explosion of brass wire by an electrical battery, the copper and zinc actually separated. He says, page 186," Brass wire is sometimes decomposed by the charge; the copper and zinc of which it is formed being separated from each other, and appearing in their distinct metallic colours." In the next page of the same work, I find that the oxides of mercury and tin are reduced by electrical discharges. "Introduce," says the author, "some oxide of tin into a glass tube, so that when the tube is laid horizontal, the oxide may cover about half an inch of its lower internal surface. Place the tube on the taule of the universal discharger, and introduce the pointed wires into its opposite ends, that the portion of oxide may lie between them. Pass several strong charges in succession through the tube, replacing the oxide in its situation, should it be dispersed. If the charges are sufficiently powerful, a part of the tube will soon be stained with metallic tin which has been revived by the action of transmitted electricity." It cannot be alleged that in such decompositions the divellent polar attractions are exercised like those which characterize the action of wire

Vol.57. No. 276. April 1821. O o proceeding 
proceeding from the poles of a voltaic apparatus. The particles were dispersed from, instead of being attracted to the wires, by which the influence was conveyed among them. This beng undeniable, it can hardly be advanced that we are to have one mode of explaining the separation of the elements of brass by an electrical discharge, another of explaining the separation of the elements of water by the same agent; one rationale when oxygen is liberated from tin, and another when liberated by like means from hydrogen. In the experiment in which copper was preeipitated by the same philosopher at the negative pole, we are not informed whether the oxygen and acid in union with it were attracted to the other; and the changes produced in litmus are mentioned not as simultaneous, but successive. The violet and red rays of the spectrum have an opposite chemical influence in some degree like that of voltaic poles, but this has not led to the conclusion that the cause of galvanism and light is the same. Besides admitting that the feeble results obtained byWollaston and Van Marum with electrical machines, are perfectly analogous to those obtained by the galvanic pile, ere it can become an objection to my hypothesis, it onght first to be shown that the union between caloric and electricity, whi:h I suppose productive of galvanic phænomena, cannot be produced by that very process. If they combine to form the galvanic fluid when extricated by ordinary galvanic action, they must have an affinity for each other. As I have suggested in my memoir, when electricity enters the pores of a metal, it may unite with its caloric. In Wollaston's experiments, being constrained to enter the metal, it may combine with enough of its caloric to produce, when emitted, results slightly approaching to those of a fluid in which caloric exists in greater proportion.

But onc more I demand, Why, if mechanical electricity be too intense to produce galvanic phæunmena, should it be rendered more capable of producing them hy being still more concentrated?

If the one be generated more copiously, the other more intensely, the frist will move in a large stream slowly, the last in a small stream rapidly. Yet by narrowing the channel of the latter, Wollaston is supposed to render it more like the former, that is, produces a resemblance by increasing the supposed source of dissimilarity.

It has been imagined that the beneficial effect of his contrivance arises from the production of a continued stream, instead of a succession of sparks; but if a continued stream were the only desideratum, a point placed near the conductor of a powerful machine would afford this requisite, as the whole product may in such cases be conveyed by a sewing needle in a stream perfectly 
continuous. As yet no adequate reasons have been given why, in operating with the pile, it is not necessary, as in the processes of Van Marum and Wollaston, to inclose the wires in glass or sealing wax, in order to make the electricity emanate from a proint within a conducting fluid. The absence of this necessity is accounted for, according to my hypothesis, by the indisposition which the electric fluid has to quit the caloric in union with it, and the almost absolute incapacity which caloric has to pass through fluids unless by circulation. I conceive that in galvanic combinations, electro-caloric may circulate through the fluid from the positive to the negative surface, and through the metal from the negative to the positive. In the one case caloric subdues the disposition which electrieity has to diffuse itself through fluids, and carries it into circulation. In the other, as metals are excellent conductors of caleric, the prodigious power which electricity has to pervade them agreeably to any attractions which it may exercise, operates almost without restraint. This is fully exemplified in my galvanic deflagrator, where eighty pairs are suspended in two recipients, forty successively in each, and yct decompose potash with the utmost rapidity, and produce an almost intolerable sensation * when excited only by fresh river water. I have alreadly observed, that the reason why galvanic apparatus composed of pairs consisting each of one copper and one zinc plate, have not acted well without insulation $\uparrow$, was because electro-caloric could retrocede in the negative, as well as advance in the positive direction. I will now add, that independently of the greater effect produced by the simultaneous immersion of my eighty coils, their power is improved by the proximity of the surfaces, which are only about 3-16ths of an inch asunder; so that the circulation may go on more rapidly.

Pursuant to the doctrine, which supposes the same quantity of electricity, varying in intensity in the ratio of the number of pairs to the quantity of surface, to be the sole agent in galvanic ignition, the electrical fluid as evolved by Sir H. Davy's great pile must have been nearly two thousand times more intense than as evolved by a single pair, yet it gave sparks at no greater distance than the thirtietl or fortieth of an inch. The intensity of the fuid must be at least as much greater in one instance, than in another, as the sparks produced by it are longer. A fine electrical plate machine of thirty-two inches diameter, will give sparks at ten inches. Of course the intensity of the fluid which it emits, must

* I do not say shock, as it is more like the permanent impression of a pointed wire, and when acid is used a hot one.

+ That is, with the same mass of conducting fluid, in contact with all the surfaces, instead of being divided into different portions, each restricted in its action to one copper and one zinc plate.

$\mathrm{O} 02$ 


\section{Galvanic Apparatus, Theory of Galvanism, \&s.}

be three hundred times greater than that emitted by two thousand pairs. The intensity produced by a single pair, must be two thousand times less than that produced by the great pile, and of course six bundred thousand times less than that produced by a good electrical plate of thirty-two inches. Yet a single pair of aticut a square foot in area, will certainly deflagrate more wire than a like extent of coated surface charged by such a plate. According to Singer, it requires about one hundred and sixty square inches of coated glass, to destroy watch pendulum wire; a larger wire may be burned off by a galvanic battery of a foot square. But agreeably to the hypothesis in dispute, it compensates by quantity, for the want of intensity. Hence the quantity of fluid in the pair is six hundred thousand times gieater, while its intensity is six hundred thousand times less; and vice versá of the coated surface. Is not this absurd? What does intensity mean as applied to a fluid? Is it not expressed by the ratio of guantity, to space? If there be twice as much electricity within one cubic inch, as within another, is there not twice the intensity? But the one acts suddenly, it may be said; the other slowly. But whence this difference? They may both have exactly the same surface to exist in. The same zinc and copper plates may be used for coatings first, and a galvanic pair afterwards. Let it be said, as it may in truth, that the charge is, in the one case, attached to the glass superficies, in the other exists in the pores of the metal. But why does it avoid these pores in one case and reside in them in the other? What else resides in the pores of the metal which may be forced out by percussion? Is it not culoric? Possibly, unless under constraint, or circumstances favourable to a union between this principle and electricity, the latter cannot enter the metallic pores, beyond a certain degree of saturation; and hence an electrical charge does not reside in the metallic coatings of a Leyden phial, though it fuses the wire which forms a circuit between them.

It is admitted that the action of the galvanic fluid, is upon or between atoms; while mechanical electricity when uncoerced, acts only upon masses. This difference has not been explained unless by my lypothesis, in which calorie, of which the influence is only exerted between atoms, is supposed to be a principal agent in galvanism. Nor has any other reason been given that water, which dissipates pure electricity, should cause the galvanic fuid to accumulate. From the prodigious effect which moist air, or a moist surface, has in paralysing the most eficient machines, I am led to suppose, that the conducting power of moisture so situated, is greater than that of water under its surface. The power of this fluid to conduct mechanical electricity, is unfairly contrasted with that of a metal, when the former is inclosed in a glass tube, the latter bare. 
According to Singer, the electrical accumulation is as great when water is used, as when more powerful menstrua are employed; but the power of ignition is warting, until these are resorted to. De Luc showed, by his ingenious dissections of the pile that electricity might be produced without, or with, chemical power. The rationale of these differences never has been given, unless by iny theory, which supposes caloric to be present in the one case, but not in the other. The electric column was the fruit of De Lue's sagacious inquiries, and afforded a beautiful and incontrovertible support to the objections he made to the idea, that the galvanic fluid is pure electricity, when extricated by the volttic pile in its usual form. It showed that a pile really producing pure electricity, is devoid of the chemical power of galvanism.

We are informed by Sir H. Davy, that when charcoal points, in connexion with the poles of the magnificent apparatus with which he operated, were first brought nearly into contact, and then withdrawn four inches apart, there was a heated arch formed hetween them, in which such non-conducting substances as quartz were fused. I believe it impossible to fuse electrics by mechanical electricity. If opposing its passage they may be broken, and if conductors near them be ignited, they may he aeted on by those ignitel conductors as if otherwise heated ; but 1 will venture to predict, that the slightest glass fibre will not enter into fusion, by being placed in a current from the largest machine or electrieal battery.

I am induced to believe, that we must consider light, as well as heat, an ingredient in the gaivanic fluid; and think it possible, that, being necessary to vitality in animals, as well as vegetables, the electric fluid may be the vehicle of its distribution.

I will take this opportunity of stating, that the heat evolved by one galvanic pair has been found by the experiments which I instituted, to increase in quantity, but to diminish in intensity, as the size of the surfaces may be enlarged. A pair containing about fifty square feet of each metal, will not fuse platina, nor deflagrate iron, however small may be the wire employed; for the heat produced in metallic wires is not improved by a reduction in their size beyond a certain point. Yet the metals above mentioned are easily fused or defiagrated by smaller pairs, which would have no perceptible influence on masses that might be sensibly ignited by larger pairs. - These characteristics were fully demonstrated, not only by my own apparatus, but by those constructed by Messrs. Wetherill and Peale, and which were larger, but less capable of exciting inteuse ignition. Mr. Peale's apparatus contained nearly seventy square feet, Mr. Wetherill's 
nearly one hundred, in the form of concentric coils, yet neither could produce a heat above redness on the smallest wires. At my suggestion, Mr. Peale separated the two surfaces in his coils into four alternating, constituting two galvanic pairs in one recipient. Iron wire was then easily burned and platina fused by it. These facts, together with the incapacity of the calorific fluid extricated by the calorimotor to permeate charcoal, next to metals the best electrical conductor, must sanction the position I assigned to it as being in the opposite extreme from the columns of De Luc and Zamboni. For as, in these, the plinomena are such as are characteristic of pure electricity, so in one very large galvanic pair, they almost exclusively demonstrate the agency of pure caloric.

XLVIII. Description of the Marine Thermometer Case invented by Mr. Robert Jamieson, of Glasgow *.

Glasgow, March 10, 1820. Sir, -1 beg leave, through you, to present for the inspection of the Society, a Marine Thermometer Case which I have constructed for Captain Livingston. The directions given to me by that gentleman, were, to make a case capable of preserving a thermometer from being broken when lowered into the sea, and drawn up again from the side of a ship; also, that it should admit water at any given depth, and retain it during the drawing up of the instrument, so as to enable a themometer of the usual construction to indicate the temperature at different depths, undisturbed by the greater or inferior heat of the surface water.

The accompanying statement, drawn up by Captain Livingston and confirmed by his own experience, of the utility of thermometrical observations to the navigator, renders wholly unnecessary any remarks of mine on the same subject. I shall therefore confine myself to the mechanical construction of the instrument as exhibited in the drawing and model herewith transmitted. In order to answer its purpose, it was necessary to combine in the construction, strength, simplicity, and portability; but although these objects have been attained so as to produce a practically advantageous result, I am far from claiming for it absolute perfection. Longer experience and greater skill will probably be able to improve upon the present first attempt; and it is with this view, and alsoin order to call the public attention to a subjert which promises to be highly beneficial to this maritime na-

* From the Transactions of the Society for the Encouragcment of Arts, Mamafactures, and Commerce, for 1820. The large Silver Medal of the Society was voted to Mr. Jamieson for this communication.

tion, 